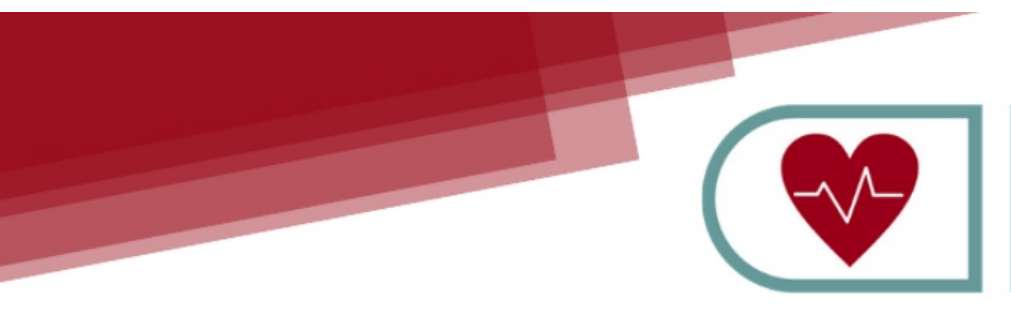

\title{
OS IMPACTOS PSICOLÓGICOS EM PACIENTES SUBMETIDOS À UNIDADE DE TERAPIA INTENSIVA: UMA REVISÃO DE LITERATURA
}

Simpósio Brasileiro Multidisciplinar De Cuidados Ao Paciente Em Terapia Intensiva., 1ạ edição, de 23/11/2020 a 26/11/2020 ISBN dos Anais: 978-65-86861-47-1

LINS; Anna Catarina Paredes Barretto ${ }^{1}$

\section{RESUMO}

Objetivos: Analisar os impactos psicológicos nos pacientes que foram internados na Unidade de Terapia Intensiva (UTI) buscando medidas para promover o bem estar mental desses pacientes durante seu período de internação. Métodos: Foram avaliados artigos através da plataforma do Scielo, Pubmed, LILACS e Google Academics com publicações entre os anos de 2010-2020. Resultados: Em um estudo com 407 pacientes, foi encontrado uma porcentagem de $14,37 \%$ que apresentaram alterações psicológicas na avaliação de seguimento três meses após a alta da UTI. Entre essas alterações os achados foram de depressão, ansiedade e sintomatologia para Transtorno do Estresse Pós-Traumático (TEPT). Através de outro artigo, foi encontrada a prevalência do TEPT entre pacientes internados em UTI variando entre $17 \%$ a $30 \%$ visto às diferenças entre os métodos avaliativos. Em uma revisão sistemática de 53 estudos, pacientes sobreviventes de UTI relataram uma menor qualidade de vida devido às alterações de ordem física, cognitiva e psiquiátrica. Muitos artigos apontam uma forte associação entre o aumento das complicações psicológicas com comorbidades associadas, uso de drogas, idade avançada e principalmente o uso de ventilação mecânica e tempo prolongado de internação, sendo esses dois fatores muito comuns entre pacientes com complicações psicológicas pósinternação. Além disso, outros fatores de risco relatados foram história prévia de ansiedade, depressão e síndrome do pânico. Conclusão: 0 presente estudo traz uma contribuição para o conhecimento das consequências psicológicas presentes em pacientes submetidos às unidades de terapia intensiva que embora não sejam tão frequentes, são relevantes para que necessite de uma atenção especial para o bem estar da desses pacientes. Essa atenção deve ser redobrada quando os fatores de forte associação estão presentes, especialmente com o uso de ventilação mecânica e tempo prolongado de internação. Contudo, essa temática ainda requer mais pesquisas para buscar mais associações causais visando a criação de novas medidas preventivas das complicações psicológicas de pacientes submetidos à internação nas unidades de terapia intensiva.

PALAVRAS-ChAVE: Unidade de Terapia Intensiva, UTI, Saúde Mental, Transtornos de Estresse Pós-Traumáticos. 